\title{
Accumulation of autoreactive effector $T$ cells and allo-specific regulatory $T$ cells in the pancreas allograft of a type 1 diabetic recipient
}

\author{
J. H. Velthuis - W. W. Unger • A. R. van der Slik • \\ G. Duinkerken • M. Engelse • A. F. Schaapherder • \\ J. Ringers • C. van Kooten • E. J. de Koning • \\ B. O. Roep
}

Received: 8 July 2008 /Accepted: 11 November 2008 /Published online: 23 December 2008

(C) Springer-Verlag 2008

\begin{abstract}
Aims/hypothesis Simultaneous kidney-pancreas transplantation is an established treatment for patients with type 1 diabetes and end-stage renal failure, even though restored beta cell function may become affected by recurrent islet autoimmunity or graft rejection. We characterised infiltrating lymphocytes isolated from a pancreatic graft with normal endocrine function in a kidney-pancreas recipient with type 1 diabetes.

Methods The pancreas graft was removed due to recurrent graft pancreatitis of unknown cause. Pancreas-infiltrating lymphocytes and peripheral blood mononuclear cells (PBMC) were isolated and characterised phenotypically and functionally.
\end{abstract}

Electronic supplementary material The online version of this article (doi:10.1007/s00125-008-1237-z) contains supplementary material, which is available to authorised users.

J. H. Velthuis · W. W. Unger · A. R. van der Slik •

G. Duinkerken $\cdot$ B. O. Roep $(\bowtie)$

Department of Immunohaematology and Blood Transfusion, Leiden University Medical Centre,

P.O. Box 9600, 2300 RC Leiden, the Netherlands

e-mail: boroep@lumc.nl

M. Engelse $\cdot$ C. van Kooten $\cdot$ E. J. de Koning

Department of Nephrology, Leiden University Medical Centre, Leiden, the Netherlands

A. F. Schaapherder $\cdot$ J. Ringers

Department of Surgery, Leiden University Medical Centre,

Leiden, the Netherlands

E. J. de Koning

Department of Endocrinology, Leiden University Medical Centre,

Leiden, the Netherlands
Results Compared with PBMC, pancreas-infiltrating lymphocytes exhibited a distinct activation/memory phenotype and $\mathrm{T}$ cell receptor profile that were indicative of selective infiltration of the pancreas. Islet autoreactive $\mathrm{CD} 8^{+} \mathrm{T}$ cells could be detected in the pancreas and were increased in frequency compared with PBMC. Additionally, an augmentation of $\mathrm{CD} 8^{+} \mathrm{CD} 28^{-}$regulatory $\mathrm{T}$ cells was observed in the pancreas; these induced expression of the inhibitory receptor immunoglobulin-like transcript-3 on antigen-presenting cells in a donor HLA class I-specific manner.

Conclusions/interpretation These data demonstrate the simultaneous presence of regulatory and effector $\mathrm{T}$ cells in the pancreas allograft of a recipient with type 1 diabetes. They also indicate that circulating islet autoreactive $\mathrm{T}$ cells may reflect immunological processes in pancreatic tissue, even though their frequency in the periphery may lead to underestimation of their presence in the pancreas. Additional specificities were also present in the pancreas that were undetectable in the circulation.

Keywords Effector T cells · Pancreas transplantation . Regulatory T cells · Type 1 diabetes
Abbreviations
APC antigen presenting cell
CCR7 chemokine (C-C motif) receptor 7
CDR3 complementarity-determining region 3
IMDM Iscove's Modified Dulbecco's Medium
IGRP islet-specific glucose-6-phosphatase catalytic subunit-related protein
ILT immunoglobulin-like transcript
mAbs monoclonal antibodies
MACS magnetic-activated cell-sorting 
NK natural killer

PBMC peripheral blood mononuclear cells

PIL pancreas-infiltrating lymphocytes

PPI preproinsulin

TCR T cell receptor

\section{Introduction}

Transplantation of pancreas or pancreatic islets of Langerhans alone or combined with a kidney graft is an established therapy for subgroups of patients with type 1 diabetes [1]. Type 1 diabetes is caused by a selective destruction of insulin-producing beta cells by autoreactive $\mathrm{T}$ lymphocytes [2-4]. Therefore, recurrent islet autoimmunity, as well as islet allograft rejection, may affect the clinical outcome of beta cell replacement therapy. Indeed, islet-specific autoreactive $\mathrm{CD} 4 \mathrm{~T}$ cells at time of transplantation [5] and increased frequencies of the circulating insulin B10-18 reactive $\mathrm{CD} 8^{+} \mathrm{T}$ cells associated with beta cell destruction [6] significantly influence clinical outcome of islet transplant recipients. Conversely, a successful transplantation is associated with absence of auto- and allo-reactivity $[5,6]$.

In recent years, several regulatory $\mathrm{T}$ cells that contribute to control of allo- and autoreactivity have been characterised: $\mathrm{CD} 4^{+} \mathrm{CD} 25^{++}$forkhead transcription factor P3-positive regulatory $\mathrm{T}$ cells [7], IL-10-secreting $\mathrm{Tr} 1$ regulatory $\mathrm{T}$ cells [8], $\mathrm{CD} 8^{+} \mathrm{CD} 28^{-}$T-suppressor cells [9] and others. Of these regulatory $\mathrm{T}$ cells, $\mathrm{CD} 8^{+} \mathrm{CD} 28^{-} \mathrm{T}$ suppressor cells have been shown to be important in clinical solid organ transplantation $[10,11]$. However, these studies were focused on circulating cells while cells residing within the transplanted organ may be better indicators of the immunological response after allogeneic transplantation.

We had the rare opportunity to study the phenotype and function of pancreas-infiltrating lymphocytes (PIL) in a recipient of kidney-pancreas allograft who had type 1 diabetes and whose pancreas allograft had to be removed due to recurrent episodes of graft pancreatitis despite normal graft endocrine function. We demonstrate that these PIL consisted of autoreactive $\mathrm{CD} 8^{+} \mathrm{T}$ cells as well as donor HLA class I-specific $\mathrm{CD} 8^{+} \mathrm{CD} 28^{-} \mathrm{T}$-suppressor cells.

\section{Methods}

Patient

A 36-year-old type 1 diabetic woman underwent simultaneous kidney-pancreas transplantation, 19 years after onset of the disease with systemic drainage of the pancreas. The immunosuppressive treatment consisted of tacrolimus, mycophenalate mofetil and prednisone. After 2 years and 7 months the pancreas graft was removed due to recurrent episodes of graft pancreatitis, often accompanied by secondarily infected peripancreatic fluid collections, for which antibiotic treatment was started. At that time the patient's $\mathrm{HbA}_{1 \mathrm{c}}$ was $5.3 \%$ and she had circulating autoantibodies against GAD65. After removal, the pancreas was immediately stored on ice, the feeding arteries of the graft were cannulated and the pancreas was flushed with ice-cold University of Wisconsin solution. The pancreas was transported in University of Wisconsin solution to the human islet isolation laboratory in the GMP facility at Leiden University Medical Centre. Pancreas digestion was performed at $37^{\circ} \mathrm{C}$ using the Ricordi method [12] and a collagenase-neutral protease enzyme solution (Serva, Heidelberg, Germany). The digest was collected in conical tubes at $4{ }^{\circ} \mathrm{C}$. After centrifugation of the conical tubes $(200 \mathrm{~g})$ the supernatant fraction was collected and stored on ice. PIL in the supernatant fraction and peripheral blood mononuclear cells (PBMC) collected before pancreatectomy were isolated by Ficoll density gradient centrifugation as described previously [13], washed twice with PBS and resuspended in Iscove's Modified Dulbecco's Medium (IMDM) with $2 \mathrm{mmol} / \mathrm{l}$ glutamine (Gibco, Paisley, Scotland) and $10 \%$ (vol./vol.) pooled human serum.

The patient gave her informed consent.

\section{Flow cytometry}

Flow cytometric studies were performed using a FACScalibur (Becton Dickinson, San Jose, CA, USA).

Phenotyping Isolated PILs and PBMC were washed with PBS containing $0.2 \%$ (wt/vol.) EDTA and $0.5 \%$ (wt/vol.) $\mathrm{BSA}$, and incubated for $30 \mathrm{~min}$ at $4^{\circ} \mathrm{C}$ with (1) FITCconjugated monoclonal antibodies (mAbs) to CD4, CD20, CD45RA, CD16c or CD25, (2) PE-conjugated mAbs to CD8, CD14, CD45RO, CD56, CD62L or CD28; (3) PerCP-conjugated CD8; (4) PE-Cy5.5-conjugated CD45RA; (5) PE-Cy7-conjugated chemokine (C-C) motif receptor 7 (CCR7); and (6) allophycocyanin (APC)conjugated mAbs to $\mathrm{CD} 3, \mathrm{CD} 4$ or $\mathrm{CD} 8$ (all Becton Dickinson). Subsequently, the cells were washed twice with PBS containing $0.2 \%$ (wt/vol.) EDTA and $0.5 \%$ (wt/ vol.) BSA and analysed on the flow cytometer.

Tetramer staining Isolated PILs and PBMC were washed with PBS containing $0.2 \%$ (wt $/ \mathrm{vol}$ ) EDTA and $0.5 \%$ (wt/vol.) BSA and incubated for $30 \mathrm{~min}$ at room temperature with PE-conjugated HLA-A2 tetramers loaded with epitopes of insulin B-chain (amino acid residues 10-18: 
HLVEALYLV), preproinsulin (PPI; residues 15-24: ALWGPDPAAA), islet-specific glucose-6-phosphatase catalytic subunit-related protein (IGRP; residues 265-273: VLFGLGFAI) or glutamic acid decarboxylase (GAD65; residues 114-123: VMNILLQYVV). Cells were washed with PBS containing $0.2 \%$ (wt/vol.) EDTA and $0.5 \%$ (wt/ vol.) BSA and co-incubated with APC-conjugated CD8 for $10 \mathrm{~min}$ at $4^{\circ} \mathrm{C}$. Subsequently, the cells were washed twice with PBS containing $0.2 \%$ (wt $/ \mathrm{vol}$.) EDTA and $0.5 \%$ (wt/vol.) BSA. Prior to analysis on the flow cytometer, 7-AAD (Becton Dickinson) was added to exclude dead cells.

T-suppressor assay $\mathrm{CD}^{+} \mathrm{CD}^{-} 8^{-} \mathrm{T}$ cells were isolated by isolating all $\mathrm{CD}^{+}{ }^{+} \mathrm{T}$ cells using a $\mathrm{T}$ cell negative isolation kit (Dynal $\mathrm{CD}^{+}$; Invitrogen, Carlsbad, CA, USA) and subsequently removing all $\mathrm{CD} 28^{+}$cells using anti-CD28 magnetic-activated cell-sorting (MACS) beads (Miltenyi, Bergisch Gladbach, Germany) according to the manufacturer's protocol. Cells were rested overnight in IMDM with $2 \mathrm{mmol} / \mathrm{l}$ glutamine (Gibco) and 10\% (vol./vol.) pooled human serum. Monocytes were isolated with anti-CD14 MACS beads (Miltenyi) and incubated overnight in IMDM with $2 \mathrm{mmol} / \mathrm{l}$ glutamine (Gibco) and 10\% (vol./vol.) pooled human serum in the presence of irradiated CD40Lexpressing cells (1:50) and purified $\mathrm{CD} 8^{+} \mathrm{CD} 28^{-} \mathrm{T}$ cells (1:1). The next day, cells were washed with PBS containing $0.2 \%$ (wt/vol.) EDTA and $0.5 \%$ (wt/vol.) BSA and incubated for $30 \mathrm{~min}$ at $4^{\circ} \mathrm{C}$ with FITC-conjugated CD86, PE-conjugated CD14 (Becton Dickinson) and PC5-conjungated immunoglobulin-like transcript (ILT-3) (Immunotech, Marseilles, France). Subsequently, the cells were washed twice with PBS containing $0.2 \%$ (wt/vol.) EDTA and $0.5 \%$ (wt/vol.) BSA and analysed on the flow cytometer.

\section{$\mathrm{T}$ cell receptor profiling}

RNA isolation, $c D N A$ synthesis and PCR RNA was isolated from PIL and PBMC using RNA BEE (Tel-Test, Friendswood, TX, USA). Using Moloney murine leukaemia virus reverse transcriptase and oligo-dT priming (Promega, Madison, WI, USA), $1 \mu \mathrm{g}$ of RNA was converted to first-strand cDNA. Each PCR reaction was set up with one of the 32 Vbeta-specific forward primers (Electronic supplementary material Table 1) and a reverse CY5-labelled primer, specific for the constant region (TgTgggAgATCTCTgCTTCTg). Aliquots of each reaction were run on agarose gel prestained with ethidium bromide, in order to compare amplicon intensities between reactions. Appropriate dilutions were performed prior to analysis when necessary.

Complementarity-determining region 3 size analysis of $T$ cell receptor Vbeta transcripts Each fluorescent Vbeta PCR product was mixed with an equal amount of formamide dye and internal size markers (Promega). The samples were loaded on a high-resolution sequencing gel (GE Healthcare, Uppsala, Sweden), run for $10 \mathrm{~h}$ on an automated DNA sequencer and analysed by DNA Fragment Manager software (GE Healthcare). The normal repertoire profile of a given T cell receptor (TCR) family takes the form of a Gaussian or nearly Gaussianlike curve consisting of multiple peaks (usually six to eight), three nucleotides apart from each other. Over-representation of a particular peak is indicative of oligoclonality.

Immunohistochemistry

Immunohistochemical stainings were performed on deparaffinised and dehydrated sections that were washed in PBS. After washing and blocking endogenous peroxidase with $0.03 \%$ (vol./vol.) $\mathrm{H}_{2} \mathrm{O}_{2}$, sections were blocked for $20 \mathrm{~min}$ with $1 \%$ (vol./vol.) normal goat serum in $\mathrm{PBS} / 1 \%$ (wt/vol.) BSA and incubated for 45 min with antibodies against CD8 (mouse monoclonal anti-human CD8 antibody [Monosan, Uden, the Netherlands]) or insulin (rabbit polyclonal antiguinea pig insulin antibody [Dako, Glostrup, Denmark]) or without primary antibody (control). After washing with PBS, sections were subsequently incubated with appropriate secondary antibodies conjugated with streptavidinhorseradish peroxidase. Antibody binding was visualised with 3,3'-diaminobenzidene as a substrate. Slides were counterstained with haematoxylin.

Lymphocyte stimulation test

PILs and PBMC were processed directly after isolation as described before [13]. Briefly, 150,000 fresh PBMCs or 100,000 PILs supplemented with 50,000 irradiated autologous $\mathrm{PBMC} /$ well were cultured in 96-well round-bottomed plates in IMDM with $2 \mathrm{mmol} / \mathrm{l}$ glutamine (Gibco) and 10\% (vol./ vol.) pooled human serum in the presence of antigen, IL-2 (35 $\mathrm{U} / \mathrm{ml}$ ) or medium alone in triplicates. After 5 days, $\left[{ }^{3} \mathrm{H}\right]$ thymidine $\left(18.5 \times 10^{3} \mathrm{~Bq}\right.$ per well) was added for $16 \mathrm{~h}$ and $\left[{ }^{3} \mathrm{H}\right]$ thymidine incorporation measured. Antigens analysed included IA-2 $(10 \mu \mathrm{g} / \mathrm{ml})$, GAD65 $(10 \mu \mathrm{g} / \mathrm{ml})$, insulin $(25 \mu \mathrm{g} / \mathrm{ml})$, insulin B10-18 $(10 \mu \mathrm{g} / \mathrm{ml})$, insulin B9-23 $(10 \mu \mathrm{g} / \mathrm{ml})$, naturally processed and presented epitopes of IA-2 [14] $\left(6.25 \mu \mathrm{g} \mathrm{ml}^{-1}\right.$ epitope $\left.{ }^{-1}\right)$ and tetanus toxoid ('third party' antigen, 1.5 flocculating units (LF)/ml). Results were interpreted as stimulation index compared with medium value, where a stimulation index of $>3$ was considered positive.

Mixed lymphocyte cultures

One-way mixed lymphocyte culture using PILs and PBMC were set up in triplicates in 96-well V-bottomed plates 
(Costar, Lowell, MA, USA) in $150 \mu$ RPMI with $2 \mathrm{mmol} / \mathrm{l} \mathrm{L-glutamine} \mathrm{(Gibco)}$ and 10\% (vol./vol.) pooled human serum. Responder cells $(40,000 \mathrm{PBMC}$ or 30,000 PILs supplemented with 10,000 irradiated autologous PBMC) were incubated with 50,000 irradiated stimulator cells (irradiated at $30 \mathrm{~Gy}$ ) per well at $37^{\circ} \mathrm{C}$ with $5 \% \mathrm{CO}_{2}$. After 5 days, the supernatant fraction was harvested and stored at $-80^{\circ} \mathrm{C}$.

Production of different cytokines was measured with Luminex technology using a human Th1/Th2 Bio-plex cytokine kit (BioRad, Veenendaal, the Netherlands), including IL2, IL4, IL5, IL10, IL12p70, IL13, granulocytemacrophage colony stimulating factor (GM-CSF), IFN $\gamma$ and TNF $\alpha$, according to the manufacturer's protocol. Briefly, antibody-coated cytokine-specific beads were added to 96-well Millipore plates (BioRad). Supernatant fractions were added for $45 \mathrm{~min}$ at room temperature in the dark while shaking at $300 \mathrm{~Hz}$, allowing cytokines to bind to the cytokine-specific beads. Subsequently, plates were washed and incubated with biotinylated anti-cytokine detection antibody for $30 \mathrm{~min}$. After washing, streptavidin PE was added for $10 \mathrm{~min}$ to bind to the detection antibody. Fluorescence labelling of cytokine-specific beads was analysed by a double-laser Bio-plex reader (Bio-Rad).
Cytokine concentration was determined based on a standard curve included in each plate, using cytokine standards provided by the manufacturer.

Statistical analysis

Statistical analysis was performed using the $\chi^{2}$ test.

\section{Results}

Phenotyping of PIL and PBMC

To determine whether the PIL constitute a specific subset of cells that migrated into the pancreas or cells that specifically expanded in the target organ, rather than representing passenger lymphocytes, we phenotypically examined the PIL and compared these to PBMC. The T cell content of the PIL was higher (87\%) than that of the PBMC (67\%), but subsequent analysis of the portion of CD4-helper and CD8cytotoxic $\mathrm{T}$ cells within all $\mathrm{T}$ cells revealed no differences in CD4 and CD8 frequencies between PIL and PBMC (Table 1). In contrast, $\mathrm{CD} 16^{-} \mathrm{CD}^{+} 6^{++}$natural killer (NK)cells were only seen in the PIL, whereas the majority of

Table 1 Lymphocyte composition of PIL and PBMC

\begin{tabular}{|c|c|c|c|c|}
\hline Cell type & Marker & PIL & PBMC & $p$ value \\
\hline $\mathrm{T}$ cells & $\mathrm{CD} 3+$ & 87 & 67 & 0.63 \\
\hline Tregs & $\mathrm{CD} 4+\mathrm{CD} 25$ bright + & 4 & 6 & \\
\hline \multirow[t]{2}{*}{ NK cells } & $\mathrm{CD} 3-\mathrm{CD} 16+\mathrm{CD} 56+$ & 0 & 9 & $0.0008^{\circ}$ \\
\hline & CD3- CD16- CD56bright + & 6 & 1 & \\
\hline B cells & $\mathrm{CD} 20+$ & 2 & 10 & \\
\hline CD4 T cells & $\mathrm{CD} 4+$ & 44 & 54 & \\
\hline Naïve & CD45RA+ & 9 & 66 & $<0.0001^{\mathrm{t}}$ \\
\hline Recently activated & $\mathrm{CD} 45 \mathrm{RA}+\mathrm{CD} 45 \mathrm{RO}+$ & 44 & 25 & \\
\hline Memory & $\mathrm{CD} 45 \mathrm{RO}+$ & 48 & 9 & \\
\hline $\mathrm{CD} 28+$ & CD28+ & 93 & 97 & \\
\hline Naïve & CCR7+ CD45RA+ & 2 & 42 & $<0.0001^{\mathrm{C}}$ \\
\hline Effector memory & CCR7- CD45RA- & 95 & 44 & \\
\hline Central memory & $\mathrm{CCR} 7+\mathrm{CD} 45 \mathrm{RA}-$ & 2 & 10 & \\
\hline CD8 T cells & $\mathrm{CD} 8+$ & 36 & 34 & \\
\hline Naïve & $\mathrm{CD} 45 \mathrm{RA}+$ & 1 & 29 & $<0.0001^{\mathrm{C}}$ \\
\hline Recently activated & $\mathrm{CD} 45 \mathrm{RA}+\mathrm{CD} 45 \mathrm{RO}+$ & 3 & 22 & \\
\hline Memory & $\mathrm{CD} 45 \mathrm{RO}+$ & 96 & 50 & \\
\hline $\mathrm{CD} 28+$ & CD28+ & 38 & 70 & \\
\hline Naïve & $\mathrm{CCR} 7+\mathrm{CD} 45 \mathrm{RA}+$ & 8 & 45 & $<0.0001^{\mathrm{C}}$ \\
\hline Effector memory & CCR7- CD45RA- & 71 & 11 & \\
\hline Central memory & CCR7+ CD45RA- & 1 & 0.3 & \\
\hline
\end{tabular}

T cells, NK cells and B cells are expressed as percentage of total lymphocytes, all other subsets as percentage of the depicted major population. ${ }^{\text {a }} p$ value calculated over distribution of NK cell subsets between PIL and PBMC; ${ }^{b} p$ value calculated over distribution of naïve, recently activated and memory CD4 T cell subsets between PIL and PBMC; ${ }^{c} p$ value calculated over distribution of naïve, effector memory and central memory CD4 T cell subsets between PIL and PBMC; ${ }^{\mathrm{d}} p$ value calculated over distribution of naïve, recently activated and memory CD8 T cell subsets between PIL and PBMC; ${ }^{\mathrm{e}} p$ value calculated over distribution of naïve, effector memory and central memory CD8 T cell subsets between PIL and PBMC 
NK-cells found in the periphery expressed CD16 and CD56. A reduced fraction of B cells was seen in the PIL (2\%) compared with $10 \%$ in peripheral lymphocytes.

Subsequent examination of the activation status of $\mathrm{CD}^{+}$ $\mathrm{T}$ cells indicated the absence of naïve $\mathrm{CD}^{+} \mathrm{T}$ cells $\left(\mathrm{CD} 45 \mathrm{RA}^{+}\right)$within the pancreas and an augmentation of memory $\left(\mathrm{CD} 45 \mathrm{RO}^{+}\right) \mathrm{CD}^{+} \mathrm{T}$ cells compared with peripheral blood. Additionally, distinction of naïve, effector memory and central memory subsets by determining the co-expression of CCR7 and CD45RA [15] confirmed the absence of naïve $\mathrm{CD} 4^{+} \mathrm{T}$ cells in the pancreas and indicated that almost all PIL $\mathrm{CD}^{+}{ }^{+} \mathrm{T}$ cells exhibited the effector memory phenotype. Similarly to the $\mathrm{CD}^{+} \mathrm{T}$ cells, naïve CD45RA ${ }^{+} \mathrm{CD}^{+} \mathrm{T}$ cells were reduced in PIL. More than $95 \%$ of $\mathrm{CD}^{+} \mathrm{T}$ cells expressed CD45RO; distinction of naïve, effector memory and central memory subsets showed that the majority of intra-pancreatic $\mathrm{CD} 8^{+} \mathrm{T}$ cells expressed the effector memory phenotype. Statistical analysis showed a significantly different distribution of $\mathrm{CD}^{+}$and $\mathrm{CD} 8^{+} \mathrm{T}$ cell subsets between PIL and PBMC. Finally, expression of the co-stimulatory molecule $\mathrm{CD} 28$ on $\mathrm{CD} 8^{+} \mathrm{T}$ cells was observed in $38 \%$ of the PIL compared with $70 \%$ of the PBMC. In conclusion, a large population of $\mathrm{CD} 8^{+}$PIL $\mathrm{T}$ cells lacked expression of $\mathrm{CD} 28$, which is consistent with a phenotype of donor-specific regulatory $\mathrm{T}$ cells $[10,16]$.

T cell receptor spectrum analysis of PIL and PBMC

An alternative method to determine whether the PIL and peripheral lymphocytes represent distinct populations was employed that analyses the spectrum of complementaritydetermining region 3 (CDR3)-length usage within the different Vbeta families of the TCRs. This has been proven to be suitable for detecting oligoclonality in transplantation [17]. Under 'normal' circumstances a Gaussian distribution within each Vbeta family is expected in polyclonal cell populations, whereas mono- or oligoclonality would lead to over-representation of a certain CDR3-length. Therefore, this method of TCR profiling allows unambiguous determination of $\mathrm{T}$ cell oligoclonality, which could be a measure of their selective expansion in response to an adaptive immune response or their selective homing to pancreatic tissue.

CDR3 usage differed between the PIL and the PBMC (Fig. 1). Analysis of CDR3 usage of PBMC showed Gaussian or near-Gaussian distributions in the majority of Vbeta families. However, within the PIL distinct nonGaussian CDR3 patterns were seen compared with PBMC; clear over-representation of CDR3 lengths indicated oligoclonality of PIL. Thus, these data confirmed the phenotypic results, indicating that PIL selectively infiltrated or expanded within the pancreas and pointing towards TCR-driven expansion of the PIL.

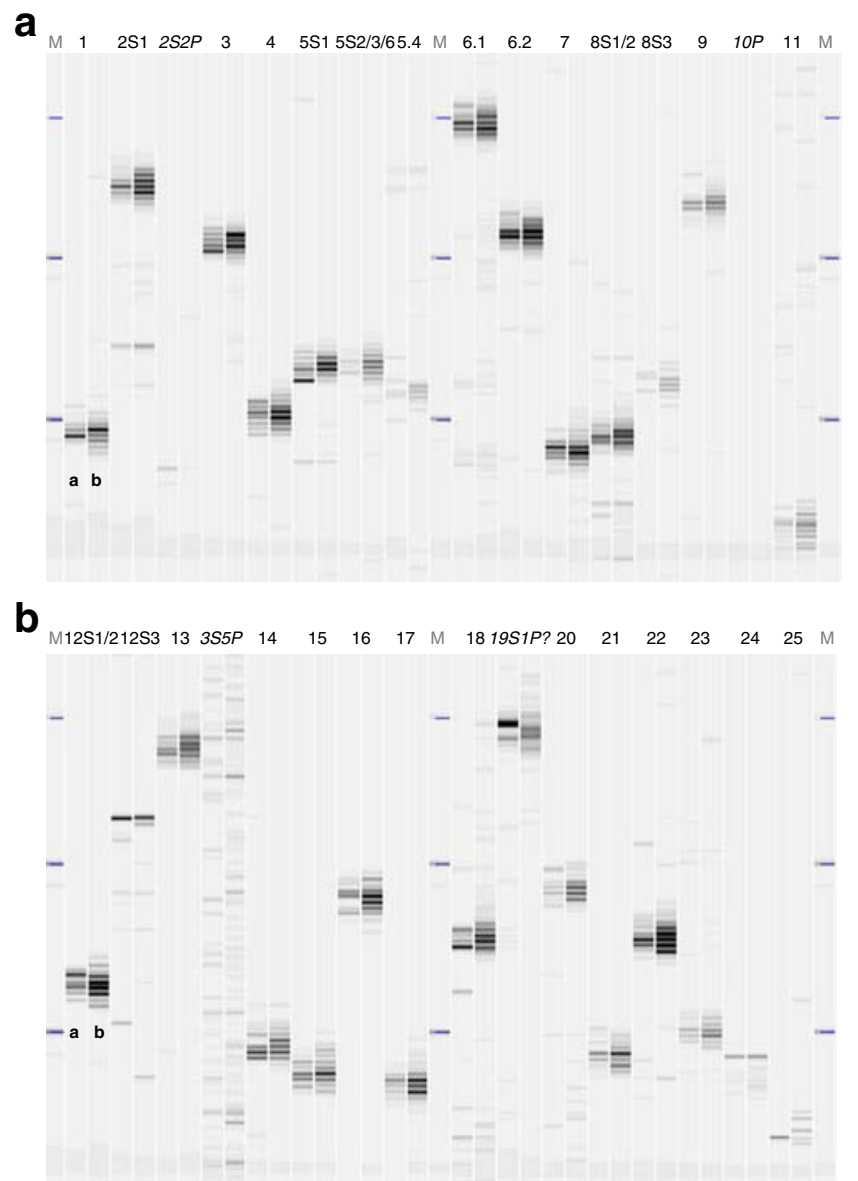

Fig. 1 PIL exhibit a distinct TCR profile. mRNA was extracted from isolated PIL and PBMC and used to synthesise cDNA. Subsequently the TCR profiles were determined using PCR probes specific for each Vbeta family and the CDR3 region, resulting in the pattern of CDR3length usage within each Vbeta family. The TCR profile of the PIL (a) is clearly distinct from that of the PBMC (b) for most Vbeta families

\section{Immunohistochemistry}

A biopsy of the explanted graft was available for immunohistochemical examination. The biopsy consisted of apparently normal pancreatic parenchyma with islets dispersed in an area of exocrine tissue (Fig. 2a). There was also a fibrotic area in the section without insulin-positive cells (Fig. 2b) or glucagon-positive cells (data not shown). Moderate CD8 infiltration was observed in the exocrine tissue (Fig. 2c). There was no sign of insulitis as CD8positive cells were not located within or surrounding the pancreatic islets in this biopsy. In the fibrotic area CD8positive cell infiltration was seen (Fig. 2d).

Autoreactive T cells in PIL and PBMC

To assess the presence of autoreactive $\mathrm{T}$ cells, we performed $\mathrm{CD} 8^{+} \mathrm{T}$ cell staining with tetramers loaded with beta cell auto-epitopes that do not require cell culture. 

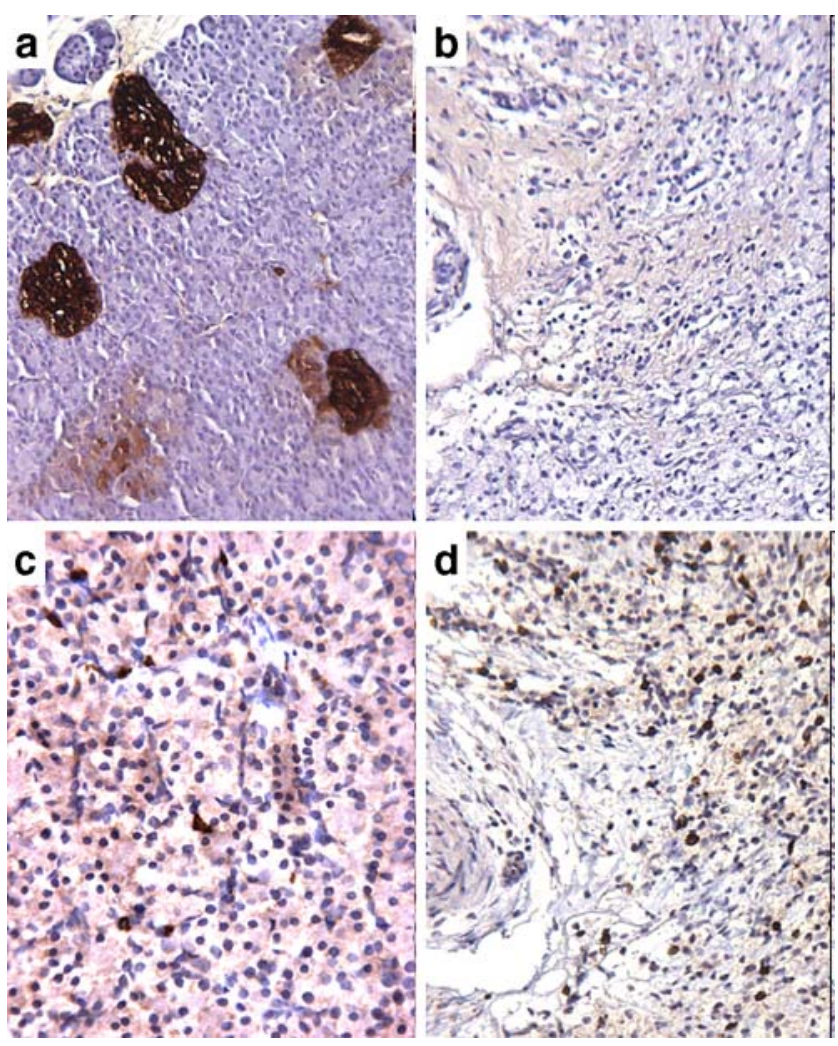

Fig. 2 Insulin-producing islets and $\mathrm{CD} 8^{+} \mathrm{T}$ cells are present in the exocrine pancreas. A tissue section from the explanted pancreas was stained for insulin $(\mathbf{a}, \mathbf{b})$ and for CD8 (c, d). Insulin-containing cells were present in islets (a) but absent within a fibrotic area (b). CD8positive cell infiltration was seen in the fibrotic area (d) and to a moderate extent in the exocrine parenchyma (c); no islets or insulitis can be seen in this panel. A total of 23 islets could be seen in this biopsy, all with apparently normal morphology and composition

Additionally, we performed a lymphocyte stimulation test in which the proliferation to diabetes antigens is measured after 5 days of culture. PIL proliferated in the presence of IL-2 or tetanus toxoid using a stimulation index of 3 as cutoff value (Fig. 3). Of the islet autoantigens, T cells only reacted to insulin, whereas none of the other antigens stimulated $\mathrm{T}$ cell proliferation. In contrast, PBMC responded to IL-2 but not to any autoantigens. Thus, insulin-reactive $\mathrm{T}$ cells were exclusively detectable in the pancreas.

As a second measure of the presence of autoreactive $\mathrm{T}$ cells, PIL and PBMC were stained with HLA-A2 tetramers loaded with the diabetes antigens insulin B10-18, PPI 1524, IGRP 265-273 and GAD65 114-123 (Fig. 4). For both populations separately, an unstained sample was used to determine a control reference. Analysis of $\mathrm{CD}^{+} \mathrm{T}$ cells within PIL showed the presence of relatively large numbers of insulin B10-18- $(1.03 \%)$ and PPI- $(0.37 \%)$ reactive $\mathrm{T}$ cells. Additionally, a small population of dimly positive cells was seen upon staining with the IGRP- and GAD65loaded tetramers. Insulin B10-18-specific CD8 T cells were

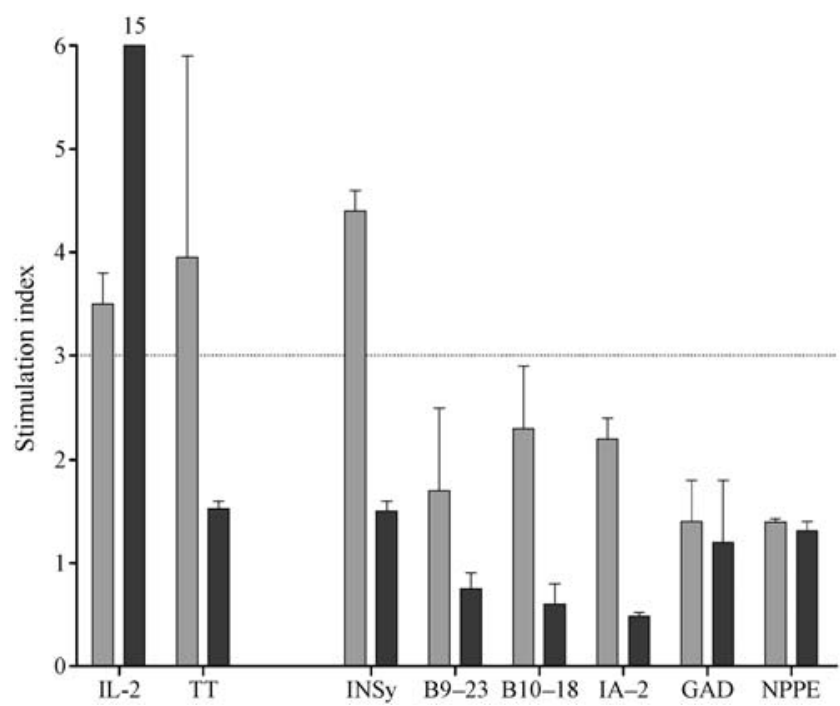

Fig. 3 PIL proliferate to whole insulin. Freshly isolated PIL (grey bars) and PBMC (black bars) were incubated for 5 days with IL-2, tetanus toxoid (TT) and a range of autoantigens associated with type 1 diabetes. At the end of day 5 , the cells were pulsed with $\left[{ }^{3} \mathrm{H}\right]$ thymidine to assess proliferation. Using a stimulation index cut-off of 3 (dotted line), the PIL responded to IL-2, tetanus toxoid and whole insulin (INSy), the PBMC only responded to IL-2. Data are depicted as mean $\pm \mathrm{SEM}$. IA2, islet antigen 2 ; NPPE, naturally processed and presented epitopes

also detectable in PBMC, albeit at lower frequency, whereas circulating CD8 T cells to the other islet epitopes were around or below their detection levels. Together, the tetramer and proliferation data indicate increased presence of islet antigen-reactive $\mathrm{T}$ cells within the pancreas.

\section{Allo-reactive T cells in PIL and PBMC}

Besides (re-)activation of autoimmunity, transplantation of a pancreas allograft may also result in activation of alloreactivity. Therefore, PIL and PBMC were co-incubated with irradiated stimulator cells expressing either pancreas donor or third party HLA class II antigens. Stimulation of PBMC with donor or third party MHC class II antigens resulted mainly in increased $\mathrm{CD} 4^{+} \mathrm{T}$ cell-mediated production of the Th1 cytokines IL- 2 and IFN- $\gamma$ as well as the Th2 cytokines IL-5 and IL-13 (Fig. 5). Unstimulated PIL produced large amounts of IL-10, which was not changed after stimulation with donor antigens. Stimulation of PIL with third party alloantigens increased IFN- $\gamma$ production.

\section{Allo-specific regulatory $\mathrm{T}$ cells}

We demonstrated an increase of islet autoreactive $\mathrm{T}$ cells within the PIL, in spite of the patient remaining insulinindependent at the time of explantation. We hypothesised 

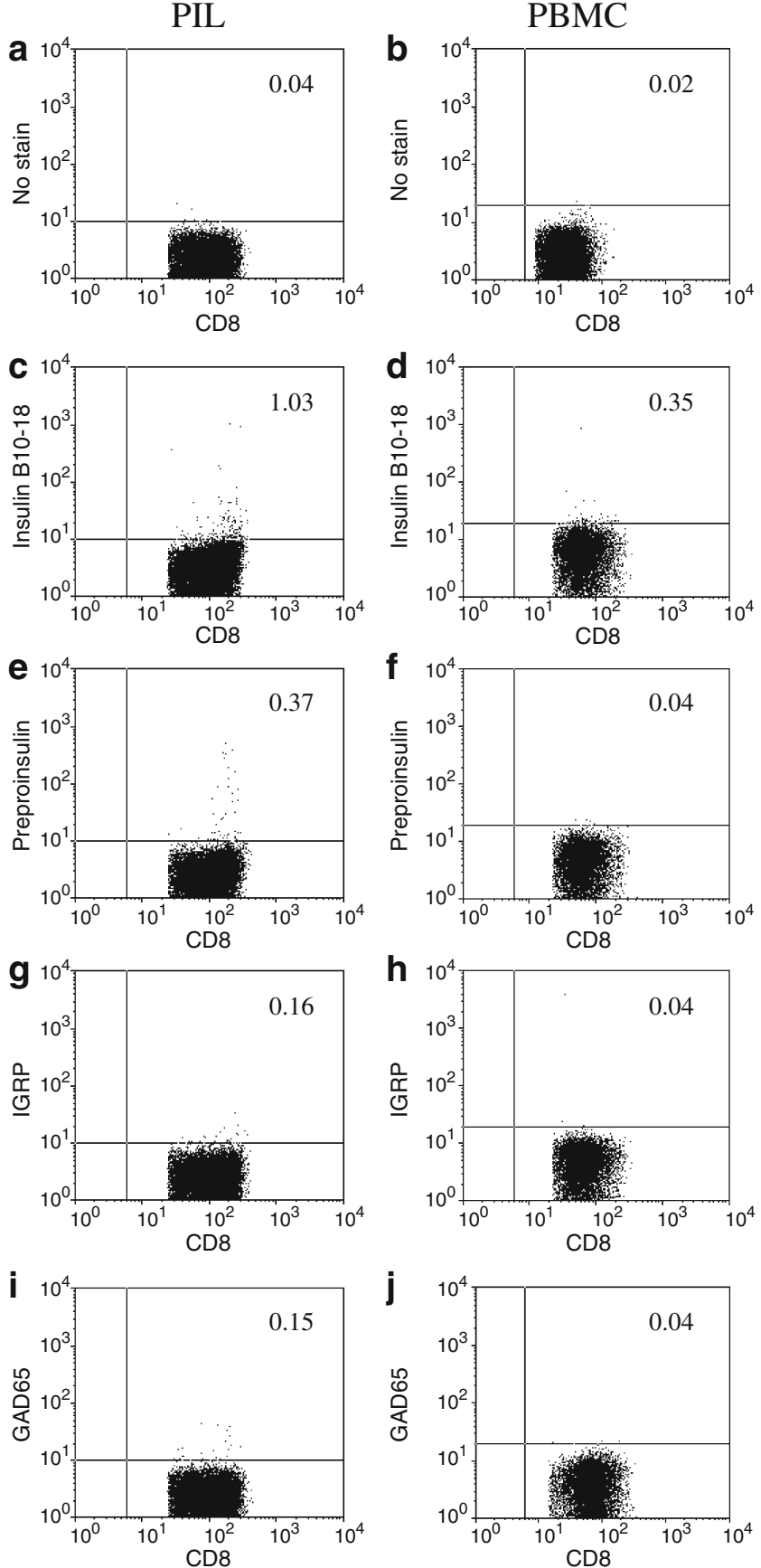

Fig. 4 Insulin B10-18- and PPI-tetramer-reactive cells are present in the PIL. PIL and PBMC were unlabelled $(\mathbf{a}, \mathbf{b})$ or stained respectively with HLA-A2 tetramers loaded with insulin B10-18 (c, d), PPI 15-24 (e, f), IGRP 265-273 (g, h) and GAD65 114-123 (i, j), and stained for expression of CD8. The frequency of tetramer-positive cells was determined by flow cytometry. $\mathrm{CD} 8^{+} \mathrm{T}$ cells responsive to insulin B10-18 and PPI 15-24 were detected within the PIL. The indicated values represent the percentage of tetramer positive cells within viable CD8+ cells

\section{a}

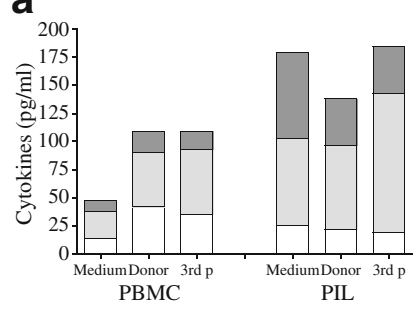

b

C

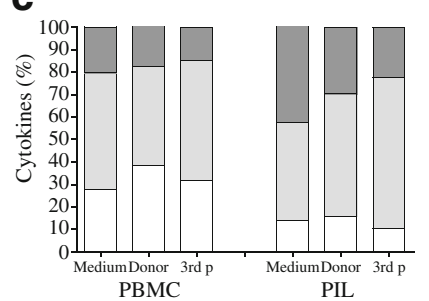

d

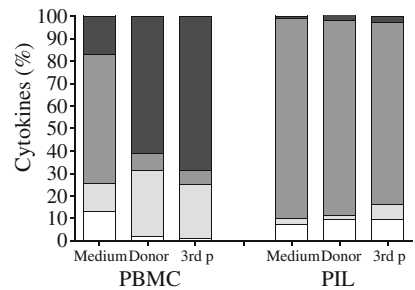

Fig. 5 Cytokine production of PIL and PBMC upon allo-stimulation. PIL and PBMC were co-incubated for 5 days with irradiated stimulator cells expressing donor HLA class II antigens or unrelated third party (3rd p) HLA class II antigens. At the end of day 5, supernatant fractions were collected and analysed. The production of Th1 (a, c) and Th2 (b, d) cytokines is depicted quantitatively $(\mathbf{a}, \mathbf{b})$ and relatively (c, d). Of the Th1 cytokines (a, c), IL-2 (white), IFN- $\gamma$ (light grey) and TNF- $\alpha$ (dark grey) were measured. Of the Th2 cytokines (b, d), IL-4 (white), IL-5 (light grey), IL-10 (dark grey) and IL-13 (black) were measured

that autoreactive $\mathrm{T}$ cells may be actively inhibited within the pancreas. Indeed, we noted an unusually large proportion of $\mathrm{CD}^{+} \mathrm{CD} 28^{-} \mathrm{T}$ cells in PIL, which has been proposed to represent an immune regulatory phenotype [911]. We therefore examined whether these cells might be capable of regulating immune effector cells. Using the system described by Sindhi et al. [11], we purified CD8 ${ }^{+}$ CD28 ${ }^{-} \mathrm{T}$ cells from PIL and co-incubated them overnight with CD40L-activated monocytes expressing either donor or third party HLA class I antigens. We then examined expression of the co-stimulatory molecule CD86 and the inhibitory molecule ILT-3 on the monocytes.

Co-incubation of $\mathrm{CD} 8^{+} \mathrm{CD} 28^{-} \mathrm{T}$ cells with activated monocytes expressing donor HLA class I molecules reduced the expression of CD86 on the APC and induced the expression of ILT-3, a marker of regulatory APCs [16] (Fig. 6). In contrast, co-incubation with monocytes expressing third party HLA class I (Fig. 6) did not result in phenotypic modulation of the APCs, indicating a regulatory mechanism specific to donor HLA class I.

\section{Discussion}

This is the first report on characterisation of PIL derived from a transplanted graft of a type 1 diabetic recipient. Lymphocytes isolated from the pancreas graft were shown 

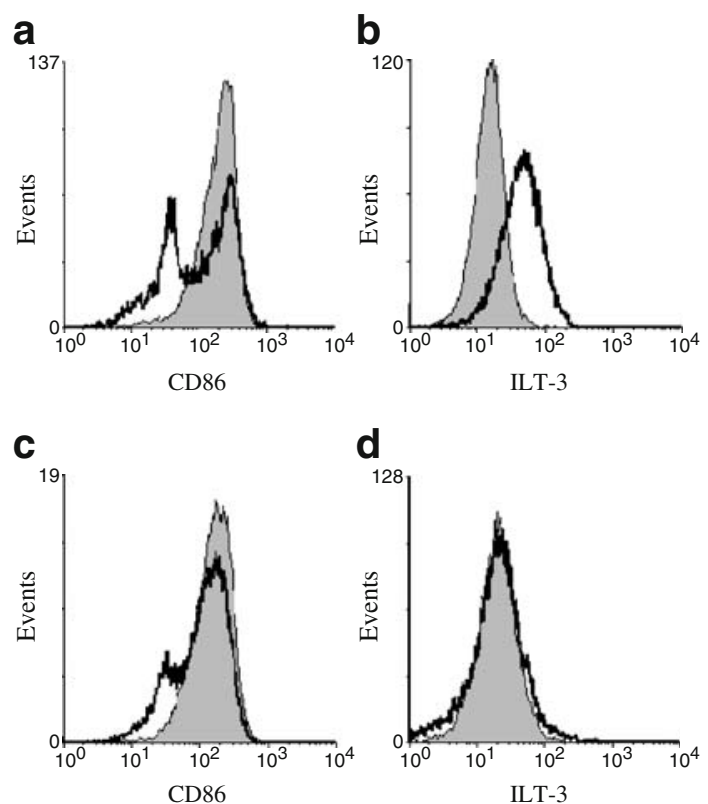

Fig. $6 \mathrm{~T}$ cells derived from $\mathrm{CD} 8^{+} \mathrm{CD} 28^{-} \mathrm{PIL}$ downregulate $\mathrm{CD} 86$ and induce expression of ILT-3 on APCs in a donor HLA class I-specific manner. $\mathrm{CD} 8^{+} \mathrm{CD} 28^{-} \mathrm{T}$ cells were isolated and co-incubated for $24 \mathrm{~h}$ with CD40L-activated monocytes that either expressed donor HLA class I $(\mathbf{a}, \mathbf{b})$ or third party HLA class I $(\mathbf{c}, \mathbf{d})$. Only when the monocytes expressed donor HLA class I was a downregulation of the costimulatory molecule CD86 (a, c) and an induction of the inhibitory molecule ILT-3 (b, d) seen. The filled histograms (grey) represent the situation without $\mathrm{CD} 8^{+} \mathrm{CD} 28^{-} \mathrm{T}$ cells; the black lines indicate the situation in the presence of $\mathrm{CD} 8^{+} \mathrm{CD} 28^{-} \mathrm{T}$ cells. Co-incubation with $\mathrm{CD} 8^{+} \mathrm{CD} 28^{+}$cells did not alter the expression of CD86 or ILT-3 (data not shown)

to exhibit a distinct phenotype versus peripheral blood lymphocytes, with the majority of pancreas-infiltrating $T$ lymphocytes expressing an effector memory phenotype indicative of selective homing. Selective presence in PIL was also observed for CD16 ${ }^{-} \mathrm{CD} 56^{+}$NK-cells. Since this subset of NK cells expresses CCR7 [18] and L-selectin [19], these NK-cells are able to interact with vascular epithelium and extravasate from blood vessels. Finally, analysis of the CDR3 length usage within the Vbeta families of the TCRs indicated oligoclonality within the PIL, which may point to selective homing, as well as to their local expansion upon TCR triggering. Altogether, these data strongly indicate selective infiltration and TCRdriven expansion of PIL.

Despite the insulin-independent status of the patient, exceptionally large numbers of autoreactive $\mathrm{T}$ cells to islet antigens were found. Previously, we showed that the presence of peripheral blood $\mathrm{CD}^{+} \mathrm{T}$ cells reactive to insulin was associated with recurrent autoimmunity and loss of beta cell function in type 1 diabetic islet transplant recipients [6]. These insulin-specific $\mathrm{T}$ cells showed potential cytolytic activity, as they produced granzyme B and IFN- $\gamma[6]$, and are therefore potentially able to destroy insulin-producing beta cells. Interestingly, an increased frequency of insulin-specific CD8 T cells was also observed in peripheral blood, whereas other islet-autoreactive cells were undetectable in the circulation. While these results confirm a selective accumulation of reactive $\mathrm{T}$ cells in the pancreas, they also indicate that peripheral measures of autoimmunity may underestimate the local responses. Indeed, circulating islet autoreactive $\mathrm{T}$ cells do not necessarily reflect their frequencies in inflammatory lesions or vice versa.

Stimulation of PIL with insulin resulted in significant proliferation, whereas other diabetes-associated islet autoantigens did not. This may be indicative of insulin as a relevant islet autoantigen. Concordantly, Kent and associates showed oligoclonality of $\mathrm{T}$ cells from pancreasdraining lymph nodes of long-standing type 1 diabetic patients proliferating to an insulin peptide epitope [20]. In contrast to the patients in their study, our recipient had no longer required exogenous insulin injection for several years, so the PIL-response to insulin cannot be attributed to a systemic anti-insulin response. Previously, we showed that in islet cell transplant recipients the presence of cellular autoreactivity influences the clinical outcome $[5,6]$ indicating the detrimental effect of autoreactive $\mathrm{T}$ cells in diabetes. Thus, as PIL consist of both proliferating and tetramer-positive autoreactive $\mathrm{T}$ cells, a potent counter mechanism needs to be active to protect beta cells from destruction and retain a state of insulin independence. Indeed, a large increase of $\mathrm{CD} 8^{+} \mathrm{CD} 28^{-} \mathrm{T}$ cells was observed in the PIL. These cells match the phenotype of donor HLA class I-specific regulatory $\mathrm{T}$ cells $[10,16]$. Functionally, the $\mathrm{CD} 8^{+} \mathrm{CD} 28^{-} \mathrm{T}$ cells induced expression of ILT-3 on donor HLA class I-expressing CD40L-activated monocytes through direct allo-recognition; expression of ILT-3 is a feature of tolerising APCs [21]. It has consistently been shown that direct CD8-APC interaction results in expression of ILT-3 and ILT-4 on the APC. This interaction requires cell-cell contact and is cytokineindependent [22]. Subsequent $\mathrm{CD} 4^{+} \mathrm{T}$ cell-APC interaction results in acquisition of a regulatory phenotype by the $\mathrm{CD}^{+} \mathrm{T}$ cell [23].

$\mathrm{CD} 8^{+} \mathrm{CD} 28^{-} \mathrm{T}$ cells have been shown to interact with human endothelial cells [24], which may act as 'target' APCs in solid organ transplantation as well as islet autoimmunity [25]. Concordantly, ILT-3 (also known as LILRB4) precursor RNA was expressed and retained in nuclei of resting endothelial cells [16]. Exposure of endothelial cells to IL-10 and IFN- $\alpha$ caused processing of ILT-3 pre-mRNA, leading to production of ILT-3 protein [16]. Thus, $\mathrm{CD} 8^{+} \mathrm{CD} 28^{-}$T-suppressor cells in the pancreas may control the effector function of autoreactive $\mathrm{T}$ cells, retaining beta cell function and insulin independence. It is tempting to speculate that the suppressive $\mathrm{CD} 8^{+} \mathrm{CD} 28^{-} \mathrm{T}$ 
cells may prevent autoreactive and alloreactive $\mathrm{T}$ cells from infiltrating the normal parenchyma of the pancreas. This would indicate that the observed $\mathrm{CD} 8^{+}$cells in the exocrine pancreas have a regulatory function. Yet, in the only tissue sample that was available for immunohistochemical analysis, CD8 cells were not located in close proximity to islets, although only 20 to 25 islets were inspected and thus insulitis could have been overlooked. Apart from showing that intact beta cells and normal islets were detectable, this finding does not directly support our hypothesis that islet autoreactivity is under control of regulatory $\mathrm{T}$ cells protecting beta cells from destruction. Nevertheless, and importantly, it does not refute our case, either. The available histology underscores that extrapolation of the immunological results to the pathogenesis of type 1 diabetes should be done with care.

Altogether, we demonstrated that a distinct population of lymphocytes was present in a chronically inflamed pancreatic allograft of an insulin-independent type 1 diabetic recipient. These infiltrating lymphocytes consisted of both autoreactive effector T cells and donor HLA class I-specific regulatory $\mathrm{T}$ cells. The composition of pancreas-infiltrating leucocytes is partly mirrored in peripheral blood. Although anecdotal, our results imply that induction of donor-specific regulatory $\mathrm{T}$ cells may allow maintenance of insulin independence after whole pancreas transplantation in spite of local islet autoimmunity. A similar balance between regulatory and effector cells is conceivable in the prodrome of type 1 diabetes.

We concede that our current study addressed inflammation of a pancreatic allograft under therapeutic immunosuppression and that extrapolation to pre-diagnosed patients should be done with care. Access to human insulitis is rarely achievable. It has been notoriously difficult to detect cellular autoreactivity in the circulation, a fact partly attributed to the presence of different types of immune regulatory mechanisms. Indeed, we obtained evidence for the coexistence of regulatory and islet autoreactive $\mathrm{T}$ cells in new-onset type 1 diabetes patients by sorting of suppressive from autoreactive $\mathrm{T}$ cell subpopulations of lymphocytes by FACS [26] or by limiting dilution [27] or by blockade of suppressive T cells [28]. In all cases, islet autoreactivity could be uncovered after interference with $\mathrm{T}$ cell regulation. We propose that our current observations are consistent with the coincident presence of regulatory and autoreactive $T$ cells that may suppress or delay islet autoimmunity and beta cell destruction and that imbalance between autoreactivity and regulation determine progression to type 1 diabetes.

Acknowledgements This research was supported by grants from the Juvenile Diabetes Research Foundation (JDRF) and the Dutch Diabetes Research Foundation (DFN).
Duality of interest The authors declare that there is no duality of interest associated with this manuscript.

\section{References}

1. Meloche RM (2007) Transplantation for the treatment of type 1 diabetes. World J Gastroenterol 13:6347-6355

2. Roep BO, Arden SD, de Vries RR, Hutton JC (1990) T cell clones from a type-1 diabetes patient respond to insulin secretory granule proteins. Nature 345:632-634

3. Roep BO (2003) The role of T cells in the pathogenesis of Type 1 diabetes: from cause to cure. Diabetologia 46:305-321

4. Atkinson MA, Eisenbarth GS (2001) Type 1 diabetes: new perspectives on disease pathogenesis and treatment. Lancet 358:221-229

5. Huurman VAL, Hilbrands R, Pinkse GG et al (2008) Cellular islet autoimmunity influences clinical outcome of islet cell transplantation. PLoS One 3:e2435

6. Pinkse GG, Tysma OH, Bergen CA et al (2005) Autoreactive CD8 $\mathrm{T}$ cells associated with beta cell destruction in type 1 diabetes. Proc Natl Acad Sci U S A 102:18425-18430

7. Sakaguchi S (2005) Naturally arising Foxp3-expressing CD25+ $\mathrm{CD} 4+$ regulatory $\mathrm{T}$ cells in immunological tolerance to self and non-self. Nat Immunol 6:345-352

8. Battaglia M, Gregori S, Bacchetta R, Roncarolo MG (2006) Tr1 cells: from discovery to their clinical application. Semin Immunol 18:120-127

9. Filaci G, Suciu-Foca N (2002) CD8+ T suppressor cells are back to the game: are they players in autoimmunity? Autoimmun Rev $1: 279-283$

10. Colovai AI, Mirza M, Vlad G et al (2003) Regulatory CD8+ $\mathrm{CD} 28-\mathrm{T}$ cells in heart transplant recipients. Hum Immunol 64:31-37

11. Sindhi R, Manavalan JS, Magill A, Suciu-Foca N, Zeevi A (2005) Reduced immunosuppression in pediatric liver-intestine transplant recipients with CD8+ CD28- T-suppressor cells. Hum Immunol $66: 252-257$

12. Ricordi C, Lacy PE, Finke EH, Olack BJ, Scharp DW (1998) Automated method for isolation of human pancreatic islets. Diabetes 37:413-420

13. Roep BO, Kallan AA, Duinkerken G et al (1995) T cell reactivity to beta-cell membrane antigens associated with beta-cell destruction in IDDM. Diabetes 44:278-283

14. Peakman M, Stevens EJ, Lohmann T et al (1999) Naturally processed and presented epitopes of the islet cell autoantigen IA-2 eluted from HLA-DR4. J Clin Invest 104:1449-1457

15. Sallusto F, Geginat J, Lanzavecchia A (2004) Central memory and effector memory $\mathrm{T}$ cell subsets: function, generation, and maintenance. Annu Rev Immunol 22:745-763:745-763

16. Kim-Schulze S, Seki T, Vlad G et al (2006) Regulation of ILT3 gene expression by processing of precursor transcripts in human endothelial cells. Am J Transplant 6:76-82

17. Hirokawa M, Matsutani T, Saitoh H et al (2002) Distinct TCRAV and TCRBV repertoire and CDR3 sequence of T lymphocytes clonally expanded in blood and GVHD lesions after human allogeneic bone marrow transplantation. Bone Marrow Transplant 30:915-923

18. Cooper MA, Fehniger TA, Caligiuri MA (2001) The biology of human natural killer-cell subsets. Trends Immunol 22:633640

19. Frey M, Packianathan NB, Fehniger TA et al (1998) Differential expression and function of L-selectin on CD56bright and CD56dim natural killer cell subsets. J Immunol 161:400-408 
20. Kent SC, Chen Y, Bregoli L et al (2005) Expanded T cells from pancreatic lymph nodes of type 1 diabetic subjects recognize an insulin epitope. Nature 435:224-228

21. Chang CC, Ciubotariu R, Manavalan JS et al (2002) Tolerization of dendritic cells by $\mathrm{T}(\mathrm{S})$ cells: the crucial role of inhibitory receptors ILT3 and ILT4. Nat Immunol 3:237-243

22. Manavalan JS, Rossi PC, Vlad G et al (2003) High expression of ILT3 and ILT4 is a general feature of tolerogenic dendritic cells. Transpl Immunol 11:245-258

23. Liu Z, Tugulea S, Cortesini R, Suciu-Foca N (1998) Specific suppression of $\mathrm{T}$ helper alloreactivity by allo-MHC class Irestricted CD8+ CD28- T cells. Int Immunol 6:775-783

24. Manavalan JS, Kim-Schulze S, Scotto L et al (2004) Alloantigen specific CD8+ CD28- FOXP3+ T suppressor cells induce ILT3+
ILT4+ tolerogenic endothelial cells, inhibiting alloreactivity. Int Immunol 16:1055-1068

25. Greening JE, Tree TI, Kotowicz KT et al (2003) Processing and presentation of the islet autoantigen GAD by vascular endothelial cells promotes transmigration of autoreactive T cells. Diabetes 52:717-725

26. Peterson LD, van der Keur M, de Vries RR, Roep BO (1999) Autoreactive and immunoregulatory $\mathrm{T}$ cell subsets in insulindependent diabetes mellitus. Diabetologia 42:443-449

27. Naik RG, Beckers C, Wentwoord R et al (2004) Precursor frequencies of $\mathrm{T}$ cells reactive to insulin in recent onset type 1 diabetes mellitus. J Autoimmun 23:55-61

28. Tree TI, Duinkerken G, Willemen S, de Vries RR, Roep BO (2004) HLA-DQ-regulated T cell responses to islet cell autoantigens insulin and GAD65. Diabetes 53:1692-1699 